\title{
Is Use of Radiation Hormesis the Missing Link to a Better Cancer Treatment?
}

\author{
Paul A. Oakley \\ Private Practice, Innovative Spine \& Wellness, Newmarket, Canada \\ Email: docoakley.icc@gmail.com
}

Received 15 June 2015; accepted 12 July 2015; published 16 July 2015

Copyright (C) 2015 by author and Scientific Research Publishing Inc.

This work is licensed under the Creative Commons Attribution International License (CC BY). http://creativecommons.org/licenses/by/4.0/

c) (i) Open Access

\begin{abstract}
Radiation hormesis is a concept that pervades radiobiological exposures; low doses enhance immune response, while higher doses inhibit immune response. Low-dose Total-Body Irradiation (TBI) therapy offers radiation treatment to cancer patients using the concepts of radiation hormesis and show very good success rates. This phenomenon has been reported elsewhere as the "abscopal effect" and considering the marginal success rates of other treatment agents, like the immunotherapy drug Ipilimumab, TBI therapy may prove to be the missing link to a better cancer treatment.
\end{abstract}

\section{Keywords}

Cancer, Radiation Hormesis, Abscopal Effect, Therapy

\section{Introduction}

Radiation hormesis is the inverted " $U$ " trend of health effects from exposure to radiation, i.e. No exposure and very high-dose exposures suppress the immune system as compared to low exposures (above zero), which actually stimulate immunity and better health (Figure 1). Radiation Hormesis was popularized in the 1980's with TD Lucky's famous book, [1] and even though it is more widely discussed recently, [2] it is far from being universally accepted.

The Linear-No-Threshold (LNT) model of radiation risk is the hallmark for radiation protection limits even though it has been criticized and proven grossly inaccurate [3]. The LNT model assumes any exposure to radiation is harmful in a linear extrapolation, which ignores the plethora of data for the healthful effects of low-dose radiation. The LNT model completely ignores the body's adaptive defenses that are triggered by low dose radiation [4].

As counter-intuitive as it may first seem to suggest exposure of radiation for enhancing health and boosting 


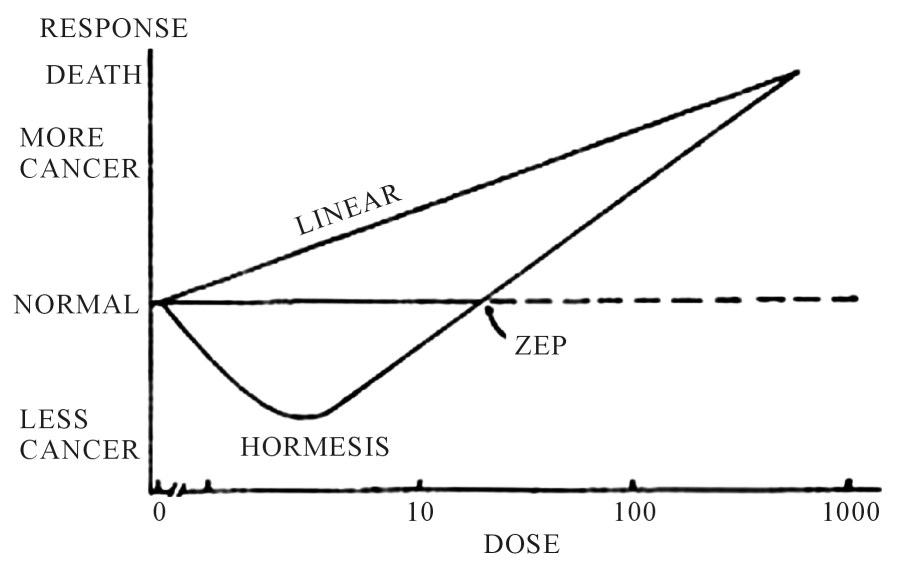

Figure 1. Linear-No-Threshold (LNT) model vs. Hormesis model of cancer incidence. Zero equivalent point (ZEP) represents highest end of the hormesis effect, where beyond initially beneficial lower exposures, these higher exposures, similar to LNT, will only increase harm (more cancers) linearly with increasing dose.

the immune system for treating and curing chronic diseases including diabetes and cancer, there is an emerging low-dose radiation therapy for treating cancer that is showing superior results.

Current use of radiation in cancer treatment is in the high-dose exposure rates to "kill" rapidly dividing cells. However, this approach is limited in its effectiveness; [5] [6] as for example, the reduction in age-adjusted cancer mortality rate has decreased only $10 \%$ in the 45 years from 1960-2005 [7].

\section{Discussion}

\subsection{First Controlled Demonstration of Radiation Hormesis on Cancer}

The therapeutic effects of X-ray for cancer treatment have shown mice with cancerous tumors could be cured by exposure to low-dose radiation. Murphy and Morton [8] treated mice by surgically removing the tumor, irradiated the mice with low-dose radiation before surgically replacing the tumor- $50 \%$ of these mice would return to perfect health, whereas the other $50 \%$ had their cancers return, but slowed 5 times longer than the controls. The control group had their tumors removed and then simply replaced-100\% were susceptible for recurrence and quickly. The authors suggested that a second radiation exposure to the treated mice would probably have been sufficient to further prolong or prevent the recurrence of the cancer altogether! Not knowing about radiation hormesis the authors suggest that the immune system could have been "vitally concerned", but they were "unwilling to commit ourselves... (however, they did say) the results... are strongly suggestive of this." This revealing study should have naturally led to human experimentation — this was published in 1915—incredibly, it would be 61 years later that this treatment would be attempted on humans.

\subsection{Low-Dose TBI Therapy}

Low-dose Total-Body Irradiation (TBI) therapy for the treatment of human cancers is the application of lowdose radiation (as opposed to high-dose localized radiation of tumors) in repeated doses over a period of five weeks (Figure 2). Alternatively, TBI can be performed by exposure of half-body irradiation. Either can be performed by exposing the patient to 150r over 5 weeks time, either two times a week in exposures of $15 \mathrm{r}$ or three times a week in exposures of 10r [9] [10].

TBI therapy was first done on humans at Harvard in the 1970s [11] [12]. The Harvard studies treated patients with non-Hodgkins lymphoma who received the standard chemotherapy as well as localized high-dose radiation of tumors but also then got TBI therapy-the 1976 [11] and 1979 [12] studies reported that the low-dose TBI groups increased the four year survival to $70 \%$ and $74 \%$ vs. the controls at $40 \%$ and $52 \%$, respectively.

Sakamoto [13] [14] also reported successful treatment of non-Hodgkins lymphoma in a group of patients who were given up on after standard chemotherapy and high-dose localized radiation. The results in his TBI-treated 


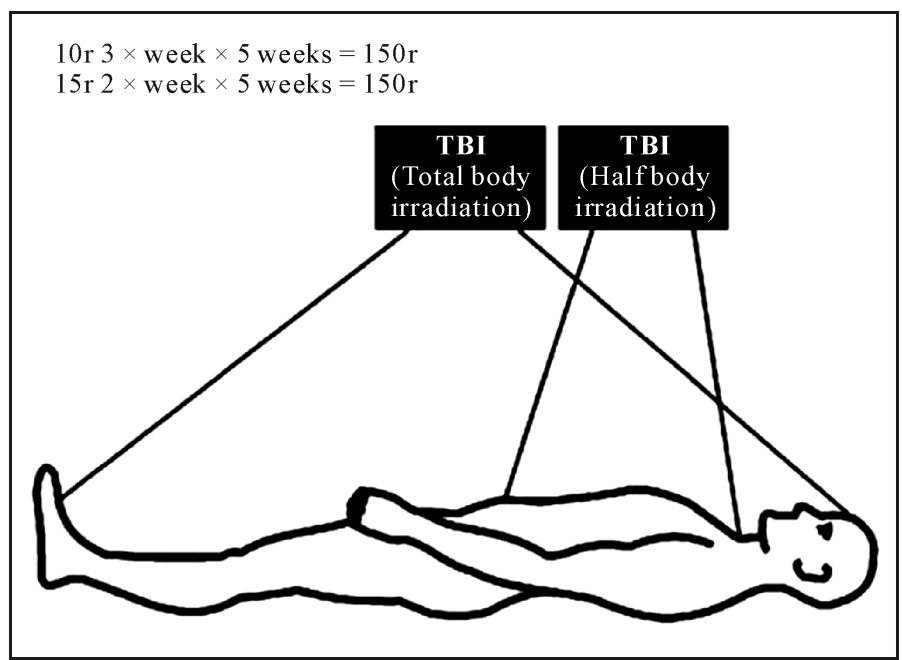

Figure 2. Low-dose Total-Body Irradiation (TBI) therapy.

patients showed a 100\% survival rate after 9 years vs. only 50\% in the non-TBI control group. It has been reported that Sakamoto has treated 150 patients during the 1990's with excellent results including "long-term cures with no symptomatic side effects" [10].

Richaud [15] reported on 26 patients treated with non-Hodgkins lymphoma by low-dose total-body irradiation followed by radical involved field radiotherapy (IF-RT). After initial TBI therapy, 24 of 26 patients were in complete remission. Following IF-RT, 25 of 26 were in complete remission. At 56 months follow-up, five patients had relapsed and 3 had died indicating at this point an $81 \%$ success rate.

Ironically, as it turns out this emerging low dose therapy has actually already been observed to occur in the odd case in patients receiving the standard cancer treatment (high-dose localized radiation). It is a phenomenon referred to as the "abscopal effect". This is described as "a phenomenon in the treatment of metastatic cancer where localized irradiation of a tumor causes not only a shrinking of the irradiated tumor but also a shrinking of tumors far from the irradiated area. While this phenomenon is extremely rare, its effect on the cancer can be stunning, leading to the disappearance of malignant growths throughout the entire body” [16].

Recent case studies have discussed this phenomenon, albeit not recognizing that it actually is an inadvertent effect of radiation hormesis. For example, on March 8, 2012 the New England Journal of Medicine [17] published a case of a patient with melanoma who, through the abscopal effect, is having successful treatment results. The patient had advanced stage melanoma that had metastasized to three other sites. The patient was being treated with a new chemotherapy agent, Ipilimumab. To help with pain, they chose to use usual high-dose localized radiation to one of the masses near the spine. They specifically stated "the right hilar lymph-node mass and spleen, which were not the target of radiotherapy, received only low, nontherapeutic doses of radiation (133 cGy and $2.3 \mathrm{cGy}$, respectively), further supporting the notion that disease regression at these distant sites was due to an enhanced systemic response."

Unfortunately, the lead author believes this case shows how adding high-dose localized radiation to the immunotherapy drug Ipilimumab in advanced cancers may lead to better results [18] —instead of considering the more likely reality that it may not have anything to do with the chemo/high-dose radiation combo at all —but only a natural expectation of an immune response from a low-dose stimulation—aka radiation hormesis.

It is forlorn when millions of dollars go towards investigating an immunotherapy drug like Ipilimumab, when its two randomized clinical trials show a survival benefit of 10\% [19] and 15\%, [20] (Sakamoto's results show a 9-year 100\% survival rate) when low-dose radiation therapy as a stand-alone treatment may prove to be superior to all the current treatments currently used to treat the various cancers as it enhances the immune system offering no significant side effects [10] [21].

Although TBI therapy remains to be studied in the varied cancer types, it has been shown to be effective in several hundred non-Hodgkins lymphoma patients [11]-[15] as well as in select cases of ovarian, colon, and hematological cancers [10] [13]. As opposed to the standard localized high-dose radiation, TBI therapy seems to physiologically encourage immunopotentiating effects [14] [22]. Overall, TBI therapy seems to be well tolerated, 
[15] where Sakamoto, one of the pioneers and surviors of this treatment [23] has found the therapy very promising except in the advanced cases and very aged patients [14].

\section{Conclusion}

Preliminary outcomes for patients with cancer treated by low-dose Total-Body Irradiation therapy has shown excellent results and has been inadvertently documented in the abscopal effect. Compared to the "standard" treatments of today, such as immunotherapy drugs and localized high-dose radiation, use of radiation in lowdoses capitalizing on the immune stimulation associated with the concept of radiation hormesis seems logical and may prove superior.

\section{References}

[1] Luckey, T.D. (1980) Hormesis with Ionizing Radiation. CRC Press, Boca Raton.

[2] Doss, M. (2013) Linear No-Threshold Model vs. Radiation Hormesis. Dose-Response, 11, 495-512. http://dx.doi.org/10.2203/dose-response.13-005.Doss

[3] Cuttler, J.M. (2013) Commentary on Fukushima and Beneficial Effects of Low Radiation. Dose-Response, 11, 447-458. http://dx.doi.org/10.2203/dose-response.13-008.Cuttler

[4] Feinendegen, L.E., Pollycove, M. and Neumann, R.D. (2013) Hormesis by Low Dose Radiation Effects: Low Dose Cancer Risk Modeling Must Recognize Up-Regulation of Protection. In: Baum, R.P., Ed., Therapeutic Nuclear Medicine, Springer.

[5] Faguet, G.B. (2005) The War on Cancer: An Anatomy of Failure, a Blueprint for the Future. Springer, Dordrecht.

[6] Goldstein, I., Madar, S. and Rotter, V. (2012) Cancer Research, a Field on the Verge of a Paradigm Shift? Trends in Molecular Medicine, 18, 299-303. http://dx.doi.org/10.1016/j.molmed.2012.04.002

[7] Remington, P.L. and Brownson, R.C. (2011) Fifty Years of Progress in Chronic Disease Epidemiology and Control. MMWR Surveill, 60, 70-77.

[8] Murphy, J.B. and Morton, J.J. (1915) The Effect of Roentgen Rays on the Rate of Growth of Spontaneous Tumors in Mice. The Journal of Experimental Medicine, 22, 800-803. http://dx.doi.org/10.1084/jem.22.6.800

[9] Pollycove, M. and Feinendegen, L.E. (2000) Cellular and Organism Dose-Response: Biopositive (Health Benefit) Effects. Proceedings of International Symposium on Health Benefits of Low-Dose Radiation-The Science and Medical Applications, Washington DC.

[10] Cuttler, J.M., Pollycove, M. and Welsh, J.S. (2000) Application of Low Doses of Radiation for Curing Cancer. Canadian Nuclear Society Bulletin, 21, 45-50.

[11] Chaffey, J.T., Rosenthal, D.S., Moloney, W.C. and Hellman, S. (1976) Total Body Irradiation as Treatment for Lymphosarcoma. International Journal of Radiation Oncology * Biology * Physics, 1, 399-405. http://dx.doi.org/10.1016/0360-3016(76)90004-3

[12] Choi, N.C., Timothy, A.R., Kaufman, S.D., Carey, R.W. and Aisenberg, A.C. (1979) Low Dose Fractionated Whole Body Irradiation in the Treatment of Advanced Non-Hodgkin's Lymphoma. Cancer, 43, 1636-1642. http://dx.doi.org/10.1002/1097-0142(197905)43:5<1636::AID-CNCR2820430512>3.0.CO;2-E

[13] Sakamoto, K., Myogin, M., Hosoi, Y., Ogawa, Y., Nemoto, K., Takai, Y., Kakuto, Y., Yamada, S. and Watabe, M. (1997) Fundamental and Clinical Studies on Cancer Control with Total or Upper Half Body Irradiation. JASTRO Japanese Society for Therapeutic Radiology and Oncology, 9, 161-175.

[14] Sakamoto, K. (2004) Radiobiological Basis for Cancer Therapy by Total or Half-Body Irradiation. Nonlinearity in Biology, Toxicology, and Medicine, 2, 293-316. http://dx.doi.org/10.1080/15401420490900254

[15] Richaud, P.M., Soubeyran, P., Eghbali, H., Chacon, B., Marit, G., Broustet, A. and Hoerni, B. (1998) Place of Low-Dose Total Body Irradiation in the Treatment of Localized Follicular Non-Hodgkin's Lymphoma: Results of a Pilot Study. International Journal of Radiation Oncology *Biology* Physics, 40, 387-390. http://dx.doi.org/10.1016/S0360-3016(97)00722-0

[16] Wikipedia (2014) Abscopal Effects.

[17] Postow, M.A., Callahan, M.K., Barker, C.A., Yamada, Y., Yuan, J., Kitano, S., Mu, Z., Rasalan, T., Adamow, M., Ritter, E., Sedrak, C., Jungbluth, A.A., Chua, R., Yang, A.S., Roman, R.A., Rosner, S., Benson, B., Allison, J.P., Lesokhin, A.M., Gnjatic, S. and Wolchok, J.D. (2012) Immunologic Correlates of the Abscopal Effect in a Patient with Melanoma. The New England Journal of Medicine, 366, 925-931. http://dx.doi.org/10.1056/NEJMoa1112824

[18] Rattue, G. (2012) Abscopal effect-When Radiation Also Destroys Non Targeted Tumors. Medical News Today, March 12. http://www.medicalnewstoday.com/articles/242784 
[19] Hodi, F.S., O’Day, S.J., McDermott, D.F., Weber, R.W., Sosman, J.A., Haanen, J.B., Gonzalez, R., Robert, C., Schadendorf, D., Hassel, J.C., Akerley, W., van den Eertwegh, A.J., Lutzky, J., Lorigan, P., Vaubel, J.M., Linette, G.P., Hogg, D., Ottensmeier, C.H., Lebbé, C., Peschel, C., Quirt, I., Clark, J.I., Wolchok, J.D., Weber, J.S., Tian, J., Yellin, M.J., Nichol, G.M., Hoos, A. and Urba, W.J. (2010) Improved Survival with Ipilimumab in Patients with Metastatic Melanoma. New England Journal of Medicine, 363, 711-723. http://dx.doi.org/10.1056/NEJMoa1003466

[20] Robert, C., Thomas, L., Bondarenko, I., O’Day, S., Weber, J., Garbe, C., Lebbe, C., Baurain, J.F., Testori, A., Grob, J.J., Davidson, N., Richards, J., Maio, M., Hauschild, A., Miller Jr., W.H., Gascon, P., Lotem, M., Har-Mankaya, K., Ibrahim, R., Francis, S., Chen, T.T., Humphrey, R., Hoos, A. and Wolchok, J.D. (2011) Ipilimumab plus Dacarbazine for Previously Untreated Metastatic Melanoma. New England Journal of Medicine, 364, 2517-2526. http://dx.doi.org/10.1056/NEJMoa1104621

[21] Pollycove, M. (2007) Radiobiological Basis of Low-Dose Irradiation in Prevention and Therapy of Cancer. DoseResponse, 5, 26-38. http://dx.doi.org/10.2203/dose-response.06-112.Pollycove

[22] Cuttler, J.M. and Pollycove, M. (2003) Can Cancer Be Treated with Low Doses of Radiation? Journal of the American Physicians and Surgeons, 8, 108-111.

[23] Sakamoto, K. (1999) Reported in Public Meetings Held in Canada, November 8-11. 